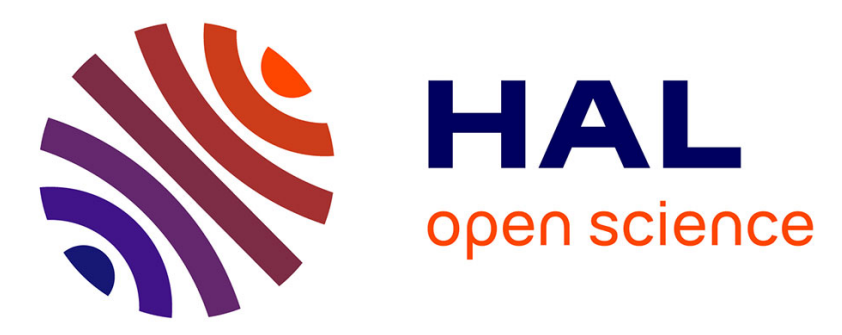

\title{
Comment on 'C. Cudennec, Y. Fouad, I. Sumarjo Gatot and J. Duchesne, a geomorphological explanation of unit hydrograph concept. Hydrological processes 18 (2004) 603-6219'
}

Cyril Fleurant, Pierre Boulestreau

\section{To cite this version:}

Cyril Fleurant, Pierre Boulestreau. Comment on 'C. Cudennec, Y. Fouad, I. Sumarjo Gatot and J. Duchesne, a geomorphological explanation of unit hydrograph concept. Hydrological processes 18 (2004) 603-6219'. Hydrological Processes, 2005, 19 (2), pp.541-543. 10.1002/hyp.5628 . hal-00735529

\author{
HAL Id: hal-00735529 \\ https://hal.science/hal-00735529
}

Submitted on 26 Sep 2012

HAL is a multi-disciplinary open access archive for the deposit and dissemination of scientific research documents, whether they are published or not. The documents may come from teaching and research institutions in France or abroad, or from public or private research centers.
L'archive ouverte pluridisciplinaire $\mathbf{H A L}$, est destinée au dépôt et à la diffusion de documents scientifiques de niveau recherche, publiés ou non, émanant des établissements d'enseignement et de recherche français ou étrangers, des laboratoires publics ou privés. 


\title{
Comment
}

\section{Comment on 'C. Cudennec, Y. Fouad, I. Sumarjo Gatot and J. Duchesne, A geomorphological explanation of unit hydrograph concept. Hydrological Processes 18 (2004) 603-621'}

\author{
C. Fleurant ${ }^{1 *}$ and P. Boulestreau ${ }^{2}$ \\ ${ }^{1}$ School of Geography and the Environment, Mansfield Road, University of Oxford, Oxford OX1 3TB, UK \\ ${ }^{2}$ French Institute of Forestry, Agricultural and Environmental Engineering, Paris, France
}

Cudennec et al. (2004) propose an original theoretical GIUH model (Rodriguez-Iturbe and Valdès, 1979) following from a coupling of general symmetry assumptions and self-similarity of river networks. This model has the originality to involve two additional disciplines: statistical physics and fractal geometry. Their paper aims to derive theoretical expressions of probability density functions (p.d.f.s) of the river network's hydraulic lengths.

Cudennec et al. (2004) clarify the p.d.f.s of hydraulic lengths in two major steps. First, by using the Strahler (1957) scheme, the authors can make an isotropy assumption on the reduced hydraulic lengths of a river network. This assumption leads to the p.d.f. of the hydraulic lengths $l_{i}$ [Equation (29) in Cudennec et al. (2004)]:

$$
\text { p.d.f. }\left(l_{i}\right)=\frac{1}{\sqrt{\pi}} \sqrt{\frac{\lambda}{r^{i-1}}} \frac{1}{\sqrt{l_{i}}} e^{-\frac{\lambda l_{i}}{r^{i-1}}}
$$

Equation (1) [or Equation (45) in Cudennec et al. (2004)] is a Gamma law with parameters $\alpha=1 / 2$ and $\beta_{i}=r_{l}^{i-1} / \lambda$. One can easily calculate that $\lambda=r^{i-1} / 2 \overline{l_{i}}$, where $\overline{l_{i}}$ is the mathematical expectation of $l_{i}$.

Our comment does not concern the first step, which is original and relevant, but the second one.

The second step aims at calculating the p.d.f. of $L$ knowing that $L=\sum_{i=1}^{n} l_{i}$ [Equation (6) in Cudennec et al. (2004)]. A classical way to calculate p.d.f. $(L)$ would have been to use the following property. If one has $n$ independent random variables $l_{i}, i=1,2, \ldots, n$ with respective p.d.f. $\left(l_{i}\right)$, then the random variable $L$ defined such as $L=\sum_{i=1}^{n} l_{i}$ has the following p.d.f.:

$$
\text { p.d.f. }(L)=\text { p.d.f. }\left(l_{1}\right) * \text { p.d.f. }\left(l_{2}\right) * \cdots * \text { p.d.f. }\left(l_{n}\right)
$$

where * is the convolution integral.

Cudennec et al. (2004) did not choose this way, but directed their reasoning towards physical considerations, aimed at expressing the variable $L$ according to $l_{i}$. The authors' result [Equation (45) in Cudennec et al. 
(2004)] is that p.d.f. ( $L$ ) is also a Gamma law with parameters $\alpha=n / 2$ and $\beta=2 \bar{L} / n$ :

$$
\text { p.d.f. }(L)=\left(\frac{n}{2 \bar{L}}\right)^{\frac{n}{2}} \frac{L^{\frac{n}{2}-1}}{\Gamma\left(\frac{n}{2}\right)} e^{-\frac{n L}{2 L}}
$$

According to the authors' assumptions, Equations (2) and (3) have to be equal. So, Cudennec et al.'s (2004) result concludes that the convolution integral of $n$ Gamma laws with different parameters $\left(\beta_{i}\right)$ also gives a Gamma law. This is definitely wrong. In fact, the use of an estimation [Equation (35) in Cudennec et al. (2004)] leads to a result [Equation (45) in Cudennec et al. (2004)] which is right only in the specific case and only for one value of the Horton's ratio $r_{1}=1$, which is indeed not a realistic value since $1.5 \leq r_{1} \leq 3.5$ in natural river networks (Rodriguez-Iturbe and Rinaldo, 1997).

We propose therefore to give the complete mathematical solution of Cudennec et al.'s (2004) problematic. Let's use the classical way stated above: if $l_{1}, l_{2}, \ldots, l_{n}$ are $n$ independent random variables distributed according to a Gamma law given by Equation (1), then what is the p.d.f. of the variable $L=\sum_{i=1}^{n} l_{i}$ ? The problematic can be solved using the calculation of the generalized characteristic functions (Sim, 1992) and the result is (details are not developed because of lack of space):

$$
\begin{aligned}
& \text { p.d.f. }(L)=\text { p.d.f. }\left(l_{1}\right) * \text { p.d.f. }\left(l_{2}\right) * \cdots * \text { p.d.f. }\left(l_{n}\right) \\
& =\left(\frac{\sum_{i=1}^{n} r_{l} r^{i-\frac{n+1}{2}}}{2 \bar{L}}\right)^{\frac{n}{2}} \frac{L^{\frac{n}{2}-1}}{\Gamma\left(\frac{n}{2}\right)} e^{-\frac{\sum_{i=1}^{n} r_{l}^{i-n} L}{2 \bar{L}}} \sum_{k=0}^{\infty} \frac{b_{n}(k)\left(\frac{n-1}{2}\right)_{k}}{k !\left(\frac{n}{2}\right)_{k}}\left(\frac{1-r_{l}^{n}}{2 \bar{L} r_{l}^{n-1} L}\right)^{k}
\end{aligned}
$$

and

$$
b_{i}(k)= \begin{cases}1, & \text { if } i=2 \\ \sum_{j=0}^{k} \frac{b_{i-1}(j)\left(\frac{i-2}{2}\right)_{j}(-k)_{j}}{j !\left(\frac{i-1}{2}\right)_{j}}(-r)^{j}, & \text { for } i=3,4, \ldots, n\end{cases}
$$

and

$$
(p)_{k}=p(p+1)(p+2) \ldots(p+k-1)
$$

In order to compare easily Equations (45) in Cudennec et al. (2004) and (4), we choose, by making a change of variables, to draw the p.d.f.s of the variable $L / L$. The p.d.f.s are drawn (Figure 1) for various values of the Horton's ratio $r_{1}$, and for various values of the Strahler's order $n$. One can see that the more $n$ or $r_{1}$ increases, the more Equations (45) in Cudennec et al. (2004) and (4) are different. Equations (45) in Cudennec et al. (2004) and (4) are equal only for $r_{1}=1$, for any value of $n$.

Many mathematical ways are then possible to prove that Equation (45) in Cudennec et al. (2004) is a particular case of Equation (4) for Horton's ratio $r_{1}=1$. The simplest is by replacing $r_{1}=1$ in Equation (4), which easily leads to Equation (45) in Cudennec et al. (2004). A more rigorous method shows that $r_{1}=1$ is the unique solution to have Equations (45) in Cudennec et al. (2004) and (4) equal. This method, following from theorems of the inverse Fourier transform and probability theory, is not developed here because of lack of space, but can be obtained from the authors.

Consequently, one can say that Equation (45) in Cudennec et al. (2004) is only a partial result since the authors' model only takes into account networks with Horton's ratio equal to 1, which is an unrealistic value in natural cases. De facto, the authors' measures of Horton's ratio are valued, not surprisingly, between 1.5 and 3. So, what is the validity of the authors' conclusions concerning their model validation comparison 

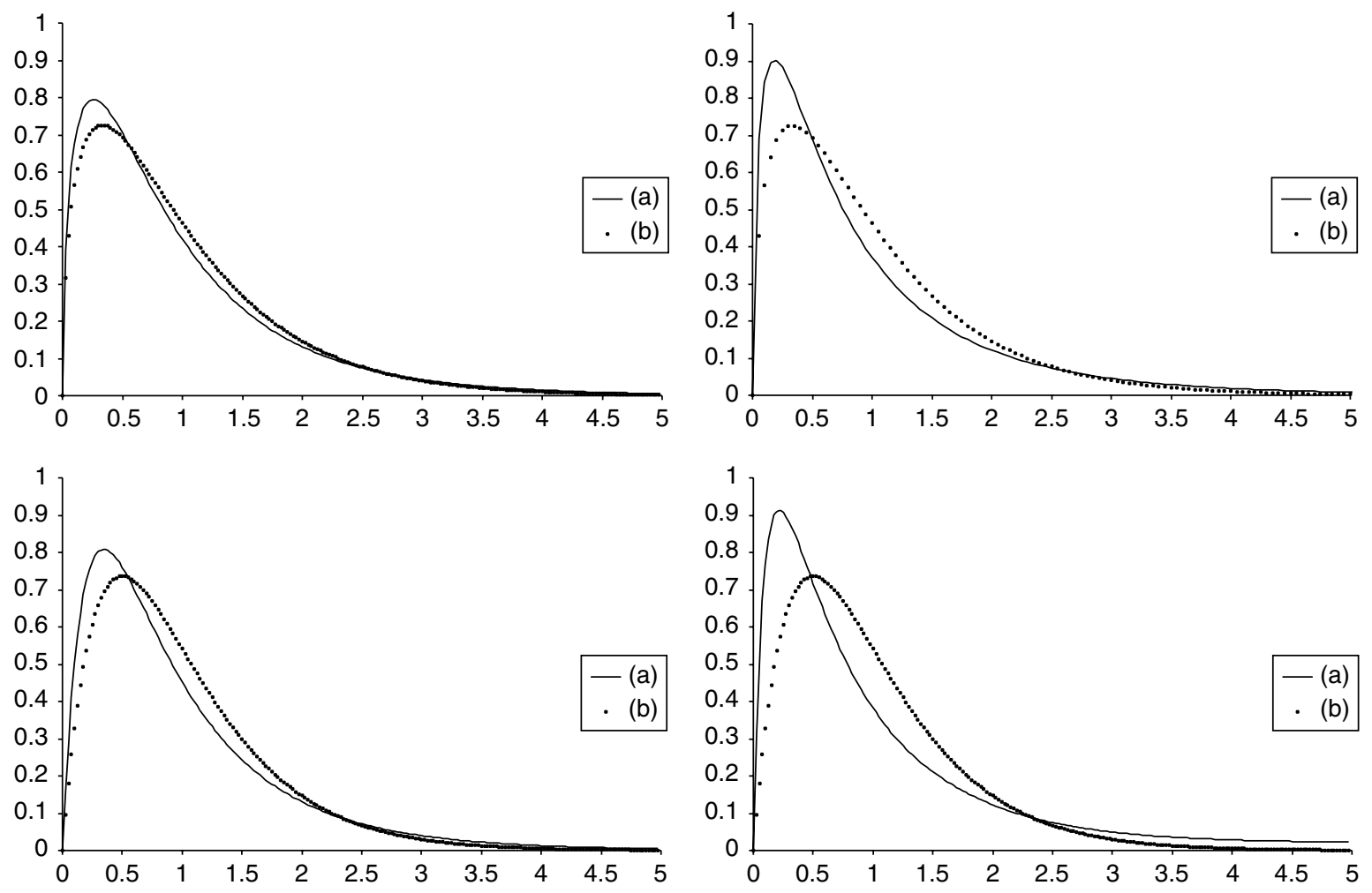

Figure 1. Comparison of the p.d.f.s: Equation (4) (a) and Equation (45) in Cudennec et al. (2004) (b). For top and bottom Figures, $n$ is 3 and 4 , successively and $r_{1}$ is 2 and 3 , respectively for left and right figures

of experimental and theoretical p.d.f.s in Figure 5 of Cudennec et al. (2004)? The skewness of the model presented here [Equation (4)] is more negative than Equation (45) in Cudennec et al. (2004), but represents the complete mathematical solution of the authors' problematic. So, is the presented model [Equation (4)] still relevant to describe real river network structures?

\section{ACKNOWLEDGEMENTS}

S. Fleurant and N. O'Dea have helped to improve and clarify the manuscript.

\section{REFERENCES}

Cudennec C, Fouad Y, Gatot IS, Duchesne J. 2004. A geomorphological explanation of the unit hydrograph concept. Hydrological Processes 18: $603-621$.

Rodriguez-Iturbe I, Rinaldo A. 1997. Fractal River Basins. Cambridge University Press: Cambridge.

Rodriguez-Iturbe I, Valdès J. 1979. The geomorphologic structure of hydrologic response. Water Resources Research 15(6): 1409-1420.

Sim C. 1992. Point processes with correlated gamma interarrival times. Statistics and Probability Letters 15: $135-141$.

Strahler A. 1957. Quantitative analysis of watershed geomorphology. Transactions of the AGU 38: 913-920. 